\title{
First report of turnip mosaic virus on yellow passion fruit in China
}

\author{
Li Juan Chen ${ }^{1} \cdot$ Xing Xing Zhang ${ }^{1} \cdot$ Ying Lin Lu ${ }^{1} \cdot$ Yu Xing An ${ }^{1}$ \\ Received: 23 September 2020 / Accepted: 21 December 2020 / Published online: 4 January 2021 \\ (C) Società Italiana di Patologia Vegetale (S.I.Pa.V.) 2021
}

Keywords Yellow passion fruit · Turnip mosaic virus · Small RNA library · RT-PCR · ELISA

Foliar virus-disease like symptoms characterized by stunting, green-yellow mosaic or necrotic spots were observed in a yellow passion fruit orchard in Dabu county, Guangdong province, southern China in December 2019. More than seventy percent of passion fruit plants in this orchard displayed virus-disease like symptoms. Leaf samples were collected from three symptomatic passion fruit plants. To identify the potential existence of viruses infecting the passion fruit, a small RNA library was constructed by using a pooled sample composed from the three plant samples, and was sequenced on an Illumina HiSeq2500 platform (Biomarker Biology Technology Ltd. Company, Beijing, China). A total of $30,811,261$ clean reads within the range of 18 to $35 \mathrm{nt}$ were assembled into larger contigs using velvet software. BLASTn and BLASTX searches against GenBank identified 50 contigs (35 to $174 \mathrm{bp}$ ) with homology (91.15 to $100 \%$ ) to turnip mosaic virus (TuMV) complete genome. These contigs covered $43.4 \%$ of TuMV genome. Sequencing also indicated the presence of cucumber mosaic virus and telosma mosaic virus, which have been reported in passion fruit (Teakle et al. 1963; Chiemsombat et al. 2014). To confirm the presence of TuMV, RT-PCR was performed using specific primers (F: 5'-GTGT ATACCCCTATCTCTAC-3' [position 8074-8093] and R: 5'-ATGGGTGAGATCCTCTTGAG-3' [position 86788697]), which was designed to amplify the partial region of the TuMV strain BJ-C4, complete genome (GenBank accession No. HQ446217.2). The expected 624-bp amplicon was amplified from all samples. Three amplicons from the three plant samples were cloned into the pMD19-T vector (TaKaRa, Dalian, China) and sequenced. Results showed that the three TuMV sequences were identical. Therefore, only one sequence was submitted to GenBank (MT982366). Nucleotide BLAST analysis revealed that TuMV isolate GD-Pf6 (MT982366) showed 97.44\% nucleotide identity to the TuMV isolate BJ-C4 (HQ446217.2), as well as the TuMV isolate CHN 12 (AY090660.1). Additionally, the three plant samples were analyzed by ELISA using commercial kits to TuMV. Results indicated that all samples were positive for TuMV in ELISA. To our knowledge, this is the first report of TuMV on cultivated yellow passion fruit in China as well as the first report of TuMV on passion fruit in the world.

Acknowledgements This work was supported by GDAS' Project of Science and Technology Development (2020GDASYL-20200103050).

\section{References}

Chiemsombat P, Prammanee S, Pipattanawong N (2014) Occurrence of Telosma mosaic virus causing passion fruit severe mosaic disease in Thailand and immunostrip test for rapid virus detection. Crop Prot 63(5):41-47

Teakle DS, Gill CC, Taylor RH, Raabe RD (1963) Cucumber mosaic virusin Passiflora in California. Plant Dis Rep 47:677-678

Publisher's note Springer Nature remains neutral with regard to jurisdictional claims in published maps and institutional affiliations.
Yu Xing An

anyuxing123@163.com

1 Institute of Bioengineering, Guangdong Academy of Sciences, Guangdong 510316 Guangzhou, People's Republic of China 